\title{
ЛИТЕРАТУРОВЕДЕНИЕ LITERATURE STUDIES
}

\author{
DOI: 10.12731/2077-1770-2018-3-12-23 \\ УДК 821.512.142.0
}

\section{ОБРАЗ И ЕГО ЗНАКОВАЯ ПРИРОДА (К ПРОБЛЕМЕ ЭТНОКУЛЬТУРНОЙ ИДЕНТИЧНОСТИ)}

\section{Узденова Ф.Т.}

Цель состоит в исследовании парадигмы национально-этнических представлений, связанных с традиционной картиной мира этноса, социально-исторической и культурно-адаптивной деятельностью; выявлении цеенностных ориентаций, или спецификатов (на различных стадиях исторического развития), обусловивших изменение в эволюционном развитии этнокультурного сознания.

Метод. В работе использованы сравнительно-исторический, структурно-семиотический, герменевтический методь.

Результатыл. Исследованы образы объектного мира, процессы их смыслопорождения, отражения и преломления в этносознании карачаево-балкариев. Выявлень образы-семы, отражающие глубинные процессы этносознания и выступающче маркерами этнокультурной идентичности. Поскольку прояснение сущности и структуры национально-этнического сознания невозможно без комплексного изучения его феноменов, объективированных в символе, анализу подвергнуты базисные кониепты. На примере кониепта «дорога/ путь» показаны особенности мировосприятия этноса, обусловленные рекреативным опытом и топологическим пониманием пути как способа познания пространства, а также сакрализацией смыслов, связанных с экзистенциальными представлениями.

Область применения результатов. Результаты исследования могут найти применение в ходе выполнения интегративных культурологических, философских, лингвистических научных проектов, исследований по семиотике. 
Ключевые слова: образ; знак; семиотика; концепт «дорога/ путь»; карачаево-балкарская поэзия; этнокультурная идентичность.

\section{IMAGE AND ITS SIGN NATURE (TO THE ISSUE OF THE ETHNOCULTURAL IDENTITY)}

\section{Uzdenova F.T.}

Purpose. The purpose is to study the paradigm of national-ethnic representations connected with the traditional picture of the world of the ethnos, socio-historical and cultural-adaptive activities, identification of core values, or specificators (at various periods of historical development) that led to a change in the evolutionary development of ethno-cultural consciousness.

Method. The work uses the comparative-historical, structural-semiotic, and hermeneutic methods of investigation.

Results. The images of the objective world, the processes of their meaning creation, reflection and refraction in the ethno-consciousness of the Karachay-Balkarians have been studied. The images-semes, reflecting the deep processes of ethno-consciousness of the Karachays and the Balkarians, thus serving as ethnocultural identity markers, have been revealed. Since the clarification of the essence and structure of national-ethnic consciousness is impossible without a comprehensive study of its phenomena objectified in the symbol, the basic concepts have been subjected to analysis. On the example of the 'road/way' concept, features of the world perception of an ethnos have been shown, conditioned by recreative experience and topological understanding of the road as a way of cognition of space, as well as sacralization of meanings connected with existential concepts.

Practical implications. The results of the research can be used in the course of the implementation of integrative cultural, philosophical, linguistic scientific projects, studies on semiotics.

Keywords: image; sign; semiotics; 'road/way'concept; Karachay-Balkar poetry; ethnocultural identity. 
На современном этапе развития национального литературоведения исследование художественных форм, этнических маркеров, посредством которых осуществляются «выходы» на этноментальную составляющую народа, наряду с проблемами генезиса и типологии приобретает четко выраженные границы. Актуализация проблемы национально-этнического, соотношения национального и инонационального, общего и особенного в традиционной картине мира карачаевцев и балкарцев «продиктована» во многом интенсивными поисками адекватной стратегии сохранения этнокультурной идентичности. Не менее значимой представляется и проблема национальной атрибутации: этнические знаки, или меты, - репрезентаты этносознания горцев. И в этом смысле прояснение сути и роли символической «форманты» в карачаево-балкарском фольклоре, путей и способов ее трансляции в авторскую литературу даст возможность обеспечить наиболее полное представление императивов, «оформляющих» национальную специфику миропонимания и мировосприятия.

Устойчивые сквозные концепты и обязательные этические и этикетные императивы, являющиеся основанием тех или иных рефлективных моделей в их этнической аутентичности, по сути дела, уже определяют национальное качество эстетических представлений. Мировоззренческая специфика и философское своеобычие национальной картины мира воплощены в сумме идей и концепций, свойственных народу-носителю.

Однако абстрактные номинации национальных концептов, пусть даже имеющие уникальный и узнаваемый вид и приобретшие форму этнозакрепленных терминов (например, «вендетта» у корсиканцев), не создают этнического пространства, хотя, конечно же, адресуют реципиента к таковому.

Лишь посредством апелляции к свойствам и характеристикам объектов этнического «окраса» мы приближаемся к конкретным идентификационным моделям. Вспомним К. Кулиева: «Хар къаяны кесини халы, / Сыфаты, тюрсюню...» [8, с. 88] («У каждой скалы свой нрав, облик, вид...»). Аналогично у Б. Лайпанова: «Хар джуртну кесини Къадау Ташы... / Хар джуртну кесини Джангыз Тереги...» 
[10, с. 61] («У каждого народа свой заветный камень, свое священное дерево...»). В общем для всех универсуме этническое сознание трактует объекты и процессы внешнего мира, сообразуясь с уникальным опытом народа, его специфическим, рекреативно детерминированным пониманием функций и места этих объектов и процессов. Исследователь 3. Кучукова соотношение понятий «онтология»«этноонтология» (собственно, в этой плоскости идет речь) проиллюстрировала на примере «дома»: «Дом - категория абстрактная, но в реальной действительности она приобретает форму хижины, хаты, землянки, бревенчатой избы, сакли, бунгало, вигвама, юрты и т.д. Каждый модифицированный вариант сохраняет в себе комплекс основных признаков дома (огороженное пространство, укрытие, защитные свойства, символическая семантика и др.), и вместе с тем он имеет специфические черты, обусловленные этническими традициями, исторической целесообразностью, климатическими условиями» [9, с. 12-13]. Нередко феномены этнокультуры рассматриваются с позиции интертекстуальности, что позволяет наряду с денотативной семантикой «проявиться» коннотативным формулам $[1 ; 2 ; 3 ; 13]$.

Примеры подобного рода связаны с особенностями этноландшафта и национальных жизнеобеспечивающих практик, однако существуют и другие типы культурных представлений, национальная окрашенность которых имеет исторически обусловленную природу. Так, через архетип пути подается мотив тоски по родине в творчестве карачаево-балкарских авторов, что, вне всякого сомнения, связано с традициями поэзии выселения. Топологическое же понимание пути как способа познания пространства, его освоения у горцев также присутствует в этнически обозначенном виде - оно непосредственно связано с образом воды по вполне понятным причинам: в горах дороги прокладываются вдоль рек. Следует отметить, что физическая близость объектов в горах (дорога, река, облако, скала, населенный пункт - всё это может располагаться в пределах одного пространства, в пределах, так сказать, одного взгляда) предопределяет изначальную взаимную интегрированность поэтических слепков этих объектов, причём не только в материальном мире, 
но также и в духовном: «Дороги кулиевских героев, возносясь из ущелий и пещер и трансформируясь в горы, олицетворяют не только земную реальность, но и сферы особого духовного состояния... Мотив дом-дорога образует композиционное кольцо в балкарской поэзии периода выселения, являясь логическим завершением темы пути в судьбе депортированного народа» [5, с. 7].

Синкретичность архетипического ядра «родина-дом-дорога» обнаруживается в четко выдержанной и стройной концепции, позволяющей идентифицировать онтологическую картину мира. Причем для горских поэтов в последовательности переходов от составляющих данного синтетического концепта обнаруживается его явная «физическая» основа - упомянутая близость и насыщенность пространства гор реальными прототипами поэтических образов гарантирует интерпретацию концепта в виде связанных, но самодостаточных картин пространственного плана. У авторов, чье мировосприятие складывалось в более «разреженной» материальной среде, трактовка линейной протяженности, как правило, предполагает непрерывность и целостность описываемого, поэтому объектом изображения в подобных случаях становятся некие умопостигаемые и единые субстанции.

Так, посредством смыслового ряда «тропинка - моя дорога путь» эвенкийский поэт А. Немтушкин («...Может, ты - моя дорога, / Самый верный в жизни путь» [11, с. 12]) осмысливает свое настоящее и прошлое, выстраивая, следовательно, хронологические константы своего национального концепта «путь», семантика которого разительно отличается от семантики его балкарской параллели. Интересно, что образ тропы введен А. Немтушкиным и в стихотворении «Улетели чирки и казарки», и здесь он символизирует уход поэта от юности; картина улетающих птиц выступает в качестве составляющей хроноархетипа «жизнь, уходящее время». Для горских поэтов, привыкших оперировать незыблемыми и константными объектами, столь неопределенная «материя», как время, естественно, не могла ассоциироваться с объектами ландшафтного ряда, и здесь мы наблюдаем некое схождение с представлениями 
эвенка - птицы могут восприниматься горцем в качестве временного образа (ср. у К. Кулиева: «Улетающие птицы» - средоточие образов-символов: уходящая молодость, неотвратимо уходящее время). «Старость и молодость, жизнь и смерть - размышлениями о подобных проблемах пронизана мировая лирика. Но каждый поэт обновляет их, осмысливая по-своему, в свете национальных и общечеловеческих традиций» [12, с. 279].

Компактность объектного ряда карачаевских и балкарских поэтов, линейная близость всех его составляющих в реальной жизни обусловили чрезвычайную демократичность эстетического ценза в процессе формирования области художественно приемлемого и используемого в текстах. Бытовые предметы, детали повседневной жизни входят в сферу осознаваемого прекрасного на равных правах с отвлеченной символикой и устойчивыми, почерпнутыми из опыта других культурных областей условно-конвенциональными формулами.

В ряде стихотворений К. Кулиева в мельчайших деталях - родина, родной край: «...и «грустные» горные дороги, деревья, задумчивые, как горянки, и навьюченные ослики, и горные орлы, перелетающие через снежные перевалы, и волчьи следы на холмах, покрытых снегом, и шум чинар, и чувяки, которые он в детстве надевал, и книга, которую впервые открыл, и руки матери, ласкавшие его... Все это было далеко во времени и пространстве, но поэт жил и дышал им. Под его пером все это превращалось в нечто значительное, приобретало зримую форму, создавая неповторимый облик Отчизны и отчего дома» [Там же. С. 242]. В данном случае мы можем говорить о символической составляющей миросозерцания поэта; вышеприведенные образы - это этнические концепты кулиевской художественно-ассоциативной поэтической системы, и их совокупность являет нам специфическую конкретику художественного мышления горцев. Для инокультуры они же (данные образы) - отвлеченные условности. Представитель другой этнокультуры оперирует совершенно иными культурными мимами и жизненными паттернами: поля, осенние леса, колосящаяся рожь - в русском эстетическом пространстве, бег оленей, снежная тундра и пороги на 
сибирских реках - в случае, например, обращения к художественным воззрениям сибирских и северных народов. Лирический герой текстов любого происхождения органичен в естественной для него объектной среде - будь это тайга, горы или степь. Это обязательное условие его внутренней гармонии.

Соответственно, глоссариальная реализация лирического героя в обязательном порядке осуществляется не только на уровне прямой номинации этноокрашенных объектов, но и в тех комплексах смыслов - вертикальных и горизонтальных, которые образуют полный семантический ореол слова, знака (эмблемы) или символа в данной культурной среде. Иначе говоря, воспринимая перечисленные форманты как маркеры национальной принадлежности текста, мы должны признать, что их аутентичность обеспечивается не только и не столько языковыми параметрами, но в основном «интегрированностью в устойчивые семантические структуры - прежде всего в архетипику национальной психологии и национального мировосприятия» [14, с. 113]. Нет сомнения, что ощущение ярко выраженной этнической поэтической речи, сохраняющееся в переводах на иные языки, обусловлено именно этим обстоятельством.

Из вышеизложенного становится очевидным, что семиосфера оформляется при четкой адресности метакодовых концептов. В случае, если мы имеем дело с отсутствием эквивалента в другой языковой картине мира, наличие семиотической составляющей, т.е. знака, не вызывает сомнений. «...Для иностранца, владеющего русским языком, словосочетания «влезть на печь», «спать на печи», «вынуть ухватом горшок из печи» будут казаться гротескными или бессмысленными, если он не представляет себе предметную область «русская крестьянская изба»» [16, с. 97]. Попадание любого текста в иноязычную или инокультурную среду выявляет ее языковые и семантические лакуны. Примерно тот же «эффект» получаем при знакомстве с фразеологическим [4; 15] и паремическим [6;7] корпусами национально-этнической традиции.

Неизбежная утеря определенных жизненных практик по мере развития общества приводит к таким же неизбежным изменениям 
информационной среды, формирующей образное мышление. Семантика образа напрямую связана с актуальным познанием окружающего. Изъятие из повседневной жизни народа тех или иных приемов адаптивного взаимодействия с окружающим закономерно сопровождается изъятием соответствующих объемов информации из образа. Содержание его сужается и в конце концов приобретает вид моносмыслового обозначения - знака, или в иных терминологических координатах - «эмблемы».

Логическая цепочка семиотических наращений и потерь, собственно, и приводит в итоге к «оформлению» презентативной этнокультурной модели, вбирающей в себя все парадигмальные и институциональные признаки этико-эстетических представлений этноса и факторы этнической идентификации.

Таким образом, можно сделать вывод о стадиальности формирования этноэстетической среды карачаевцев и балкарцев, необходимости взаимодействия с другими системами (в плоскости общее-особенное), соотношении процессов культурного развития, обеспечивающих адекватное представление о национальной идентичности и способах ее определения. В результате проведенного анализа концептуальных учений и текстового материала:

- исследованы процессы эволюционирования национальных форм символизации, позволяющих сформировать представление об особенностях национально-этнического сознания;

- отмечена необходимость концептуального рассмотрения семиотической составляющей в плоскости архетип-символзнак;

- выявлены концепты и императивы (особенности их отражения и преломления в этносознании карачаевцев и балкарцев) и их знаковая природа.

\section{Список литературы}

1. Атабиева А.Д. Характер употребления пространственно-временных символов в национальной прозе // Филологические науки. Вопросы теории и практики. 2016. № 7-1 (61). С. 18-20. 
2. Ахматова М.А., Кетенчиев М.Б. Интертекстуальность как облигаторный признак карачаево-балкарского нартского эпоса // Вестник Челябинского государственного университета. 2013. № 2 (293). С. $68-70$.

3. Базиева Г.Д. Этнические традиции и современные инновации в художественных текстах. Нальчик: Издательский отдел ИГИ КБНЦ PAH, 2017. $167 \mathrm{c}$.

4. Гузеев Ж.М., Улаков М.З. Фразеология современных тюркских языков и проблемы ее словарной разработки // В пространстве языка и культуры: звук, знак, смысл: сб. статей в честь 70-летия В.А. Виноградова. Cep. «Studia Philologica». Российская академия наук, Институт языкознания. М., 2010. С. 179-187.

5. Джанхотова 3.Х. Система архетипических образов в балкарской поэзии 30-50-х гг. XX века (на материале произведений К. Кулиева): автореф. дис. ... канд. филол. наук. Нальчик, 2010. 23 с.

6. Жекеева Е.3., Габуниа 3.М., Улаков М.З. К проблеме оценочного характера пословичной картины мира // Известия Кабардино-Балкарского научного центра РАН. 2011. № 2. С. 140-147.

7. Кетенчиев М.П. Карачаево-балкарские компаративные паремические высказывания // Актуальные проблемы филологии и педагогической лингвистики. 2015. № 2 (18). С. 132-136.

8. Кулиев К. Собрание сочинений в трёх томах (Жазгъанларыны юч томлу жыйымдыгъы). На балк. яз. Нальчик: Эльбрус, 1981. Т. 1. 600 с.

9. Кучукова 3.А. Онтологический метод как ядро этнопоэтики. Нальчик: Изд-во М. и В. Котляровых, 2005. 312 с.

10. Лайпанов Б. Одинокое дерево на Родине (Джуртда Джангыз Терек): стихи (на карач. яз.). М.: Молодая гвардия, 1992. 256 с.

11. Немтушкин А. Костры моих предков. Стихи. Красноярск, 1980. C. 12 [Электронный ресурс] // Литературная учеба. 2002. № 1. URL: http:// www.imli.ru/structure/theory/projects.php (дата обращения: 12.05.2012).

12. Толгуров 3.Х. Кайсын Кулиев // Очерки истории балкарской литературы. Нальчик: Республиканский полиграфкомбинат им. Революции 1905 г., 2010. С. 228-281. 
13. Узденова Ф.Т. Семиотический контекст и национальная идентичность: к методологии вопроса // Известия Кабардино-Балкарского научного центра РАН. 2015. № 3 (65). С. 294-300.

14. Узденова Ф.Т. Художественное пространство карачаево-балкарской поэзии: этнокультурный контекст. Нальчик: Принт Центр, 2016. 212 с.

15. Хуболов C.M. Семантические разряды компаративных фразеологизмов в карачаево-балкарском языке // Известия Кабардино-Балкарского научного центра РАН. 2015. № 1(63). С. 290-294.

16. Шафиева М.А. Взаимодействие языка и культуры в семиотическом аспекте // Вестник Самарского государственного университета. 2008. № 63. C. 94-99.

\section{References}

1. Atabiyeva A.D. Harakter upotreblenija prostranstvenno-vremennyh simvolov v nacional'noj proze [The Specifics of the Use of Spati-temporal Symbols in the National Prose]. Filologicheskie nauki. Voprosy teorii i praktiki, no 7 (2016): 18-20.

2. Akhmatova M.A., Ketenchiyev M.B. Intertekstual'nost' kak obligatornyj priznak karachaevo-balkarskogo nartskogo jeposa [Intertekstuality as an Obligatory Feature of the Karachay-Balkarian Nart Epic]. Vestnik Cheljabinskogo gosudarstvennogo universiteta, no 2 (2013): $68-70$.

3. Baziyeva G.D. Jetnicheskie tradicii $i$ sovremennye innovacii v hudozhestvennyh tekstah [Ethnic Traditions and Modern Innovations in Literary Texts]. Nalchik: Izdatel'skij otdel IGI KBNTs RAS, 2017. 167 p.

4. Guzeev Zh.M., Ulakov M.Z. Frazeologija sovremennyh tjurkskih jazykov i problemy ee slovarnoj razrabotki [Phraseology of Modern Turkic Languages and the Problem of its Development in Dictionaries]. $V$ prostranstve jazyka i kul'tury: zvuk, znak, smysl [In the space of language and culture: sound, sign, meaning]: sb. statej v chest' 70-letija V.A. Vinogradova. Ser. «Studia Philologica». Rossijskaja akademija nauk, Institut jazykoznanija. M., 2010: 179-187.

5. Dzhankhotova Z.H. Sistema arhetipicheskih obrazov v balkarskoj pojezii 30-50-h gg. XX veka (na materiale proizvedenij K. Kulieva) [The 
System of Archetypic Images in the Balkar Poetry of the 30-50s of the 20th century (on the material of works by K. Kuliyev)]. Nalchik, 2010. $23 \mathrm{p}$.

6. Zhekeeva E.Z., Gabunia Z.M., Ulakov M.Z. K probleme ocenochnogo haraktera poslovichnoj kartiny mira [On the Issue of the Estimation Character of the Proverbial Picture of the World]. Izvestija Kabardino-Balkarskogo nauchnogo centra RAN, no 2 (2011): 140-147.

7. Ketenchiyev M.P. Karachaevo-balkarskie komparativnye paremicheskie vyskazyvanija [The Karachaevo-Balkar Comparative Paroemiac Utterances]. Aktual'nye problemy filologii i pedagogicheskoj lingvistiki, no 2 (2015): 132-136.

8. Kuliyev K. Sobranie sochinenij v trjoh tomah [Collected Works in Three Volumes]. Nalchik: Elbrus, 1981. V. 1.600 p.

9. Kuchukova Z.A. Ontologicheskij metod kak jadro jetnopojetiki [The Ontologic Method as the Core of the Ethnopoetics]. Nalchik: Izd-vo M. i V. Kotljarovy, 2005. 312 p.

10. Laypanov B. Odinokoe derevo na Rodine [A Lonely Tree of the Homeland]. Moscow: Molodaja gvardija, 1992. 256 p.

11. Nemtushkin A. Kostry moih predkov [Fires of my Ancestors]. Stikhi. Krasnoyarsk, 1980. P. 12. Literaturnaja ucheba, no 1 (2002). http:// www.imli.ru/structure/theory/projects.php (date of access: 5.12.2012).

12. Tolgurov Z.H. Kaysyn Kuliyev. Ocherki istorii balkarskoj literatury. Nal' chik: Respublikanskij poligrafkombinat im. Revoljucii 1905 g. [Essays on the history of Balkarian literature. Nalchik: Republican Polygraph Complex Revolution of 1905], 2010: 228-281.

13. Uzdenova F.T. Semioticheskij kontekst i nacional'naja identichnost': k metodologii voprosa [Semiotics Context and National Identity: Concerning the Methodology of the Issue]. Izvestija Kabardino-Balkarskogo nauchnogo centra RAN, no 3 (2015): 294-300.

14. Uzdenova F.T. Hudozhestvennoe prostranstvo karachaevo-balkarskoj pojezii: jetnokul'turnyj kontekst [The Artistic Space of the Karachay-Balkarian poetry: the Ethnocultural Context]. Nalchik: Print Centr, 2016. 212 p. 
15.Hubolov S.M. Semanticheskie razrjady komparativnyh frazeologizmov v karachaevo-balkarskom jazyke [Semantic Categories the Comparative Phraseological Units in the Karachay-Balkar language]. Izvestija Kabardino-Balkarskogo nauchnogo centra RAN, no 1(2015): 290-294.

16. Shafiyeva M.A. Vzaimodejstvie jazyka i kul'tury v semioticheskom aspekte [Interaction of Language and Culture in the Semiotic Aspect]. Vestnik Samarskogo gosudarstvennogo universiteta, no 63 (2008): 94-99.

\section{ДАННЫЕ ОБ АВТОРЕ}

Узденова Фатима Таулановна, старший научный сотрудник сектора карачаево-балкарской литературы, кандидат филологических наук

Институт гуманитарных исследований - филиал Федерального государственного бюджетного научного учреждения «Федеральный научный иентр «Кабардино-Балкарский научный иентр Российской академии наук» (ИГИ КБНЦ РАН) ул. Балкарова, 2, г. Нальчик, Кабардино-Балкарская Республика, 360002, Российская Федеращчи uzdenova_kbigi@mail.ru

\section{DATA ABOUT THE AUTHOR}

Uzdenova Fatima Taulanovna, Senior Staff Scientist of the Sector of Karachay-Balkar Literature, Ph. D. in Philology Institute for the humanities research - Affiliated Federal State Budgetary Scientific Establishment "Federal Scientific Center "Kabardian-Balkarian Scientific Center of the Russian Academy of Sciences" (IHR KBSC RAS)

2, Balkarova Str., Nalchik, Kabardino-Balkaria, 360002, Russian Federation

uzdenova_kbigi@mail.ru

SPIN-code: 1956-8363

ORCID: 0000-0002-5378-9514 